\title{
Editorial Introduction: Special Topics Issue on Other Animals
}

\section{Lisa Guenther And CHLOË TAYlor}

Other Animals began as a search for papers for a day-long conference panel on "Recent Perspectives on Animals in Continental Philosophy," organized by the editors of this issue for the annual conference of the Society for Existential and Phenomenological Theory and Culture/Théorie et culture existentialistes et phénoménologiques (EPTC/TCEP) at the University of Saskatchewan in May 2007. We organized this conference panel to explore and to participate in the recent, exciting flurry of interest in non-human animals in continental philosophy, which had long lagged behind analytic philosophy in taking up this crucial philosophical and ethical concern. Many of the papers in this issue-those by Astrida Neimanis, Lori Brown, Emma Jones, and Brett Buchanan-are revised versions of papers which were presented at this conference. Additional papers were invited from Kelly Oliver, David Morris, and Karen Houle, while papers from Lisa Guenther, Bryan Smyth, Christiane Bailey, and Josh Hayes, as well as a poem by Mariianne Mays, resulted from our call for submissions. We are very pleased with the range of papers that we were able to include in this issue, which consider the role of animals in the spectrum of continental thought, from Heidegger, Merleau-Ponty, and Levinas, to Derrida and Deleuze. This is also the first issue of PhaenEx to include review essays, or Book Encounters. The books encountered in this issue are Mark Kingwell's Nearest Thing to Heaven: 
The Empire State Building and American Dreams, reviewed by Tracey Nicholls, and Simon Critchley's Infinitely Demanding: Ethics of Commitment, Politics of Resistance, discussed by Peter Gratton.

We would like to thank all of those who participated in and organized the original EPTC/TCEP conference, as well as the reviewers for PhaenEx, who must remain anonymous. Thank you also to Angela Petsis for the cover photograph, entitled, "Mysteries \#1 (Fear of the Unknown)." Angela is a mixed media artist and photographer; please visit

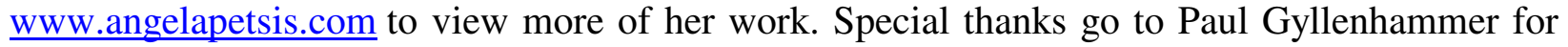
all his help and advice with this issue. 